DE

DE GRUYTER

OPEN

G

10.1515/topling-2017-0001

\title{
The "hamburger" story; or on Anglicisms in Polish
}

\author{
Krzysztof Polok \\ University of Žilina, Slovakia
}

\begin{abstract}
The paper makes an attempt to analyse the forms of co-functioning of world languages, taking into account the fact that popular prestigious languages exert influence upon a number of less popular ones, thereby dictating the forms of their further development. Thus, the thesis that media-favoured languages used by politically salient super-powers effectively influence the expressions accepted in a number of "less successful" languages is identified, evidenced and diagnosed. Furthermore, the latter part of the paper stresses the issues concerning the observation that English, recognized as the most prominent donor language, creates many forms of description generally used in many other languages to denote and define similar forms of experiences. Research aimed at discovering the ways in which English influences recipient languages, in this case Polish, was carried out. Our principal assumption was that there exist at least two types of numerous contacts between a donor and recipient language: ones that can be called external (when the donor language mostly influences the recipient one) and ones possibly labelled as internal (when various, normally observed forms of co-operation between the two languages can be traced). As in both cases some semantic bonds can be found, the subsequent research describes said bonds, naming them and uncovering the nature of such co-existence. The results of the research indicate clear forms of semantic co-existence showing that numerous borrowings and loanwords found in the recipient language are widely verbalized and deeply ingrained in the cultural linguistic interdependencies.
\end{abstract}

\section{Key words}

culture and language coexistence, linguistic environment, information dissemination, media favoured languages, language functioning, global language

In making an attempt to analyse the forms of development of language, and partly to understand its ever-vital existence, one has to take into account the functioning of the second element of this co-occurrence, which not only explains its current existence, but also helps in its growth and development, i.e. culture. Such an approach appears to be of particular importance in defining the position culture is generally expected to hold when confronted with either the notion of teaching/using global English for the purpose of message transfer, or its imaginable perception as an element of everlasting language back-up. This approach appears to retain particular prominence in the theses offered by Phillipson (1993).

Consequently, Phillipson raises an objection towards the general and not always necessary acceptance of English as the most important language of common communication, stating that this form of acceptance, in a way, relegates the natural, native language. Such an approach results, following Phillipson's stance, in the appearance of a large and statistically important number of expressions/phrases which, while actually having been borrowed from the language intrinsically alien to the sources 
responsible for the development of the mother tongue, are eventually recognized as native by a large majority of the people functioning in a given geographical area. Naturally, following the presented stance, such an approach must influence (if not change) the forms of everyday reasoning of many (if not most) of the users of a given community, resulting in the adoption of a number of expressions/phrases/grammatical structures so far unknown in the language. A situation like this may sometimes result in the demise of a language (cf. A. Schmidt, Young People's Dyirbal, 1985, p.127). Nevertheless, even when the language is not in danger of extinction, it is still experiencing a number of changes that will result in the general diminution of the growth of relative importance/prestige. In the overall, subjectively formed, ranking of languages the basic elimination asset is the relative amount of voluntarily accepted loanwords found to be functioning in other world languages. The very fact that a given language has recognized and used a loanword helps in the growth of internal prestige of the donor language in question. Let us present some of the issues concerning language and culture co-existence.

\section{Mutual forms of co-occurrence of language and culture}

The fact that languages reveal one's ethnic philosophy and character was observed more than a century ago when people discovered that different words to describe a seemingly identical idea were used. Years of detailed study expounding this language phenomenon resulted in an infinite number of definitions/elaborations that have permitted people to understand the very idea of communication. Language seems to employ numerous paths in evoking contextual concepts belonging to the multilingual ethnic environment. Undoubtedly, language is an indispensable tool so instrumental in life and communication within a given society that even mute people must work out some form of verbalization of their thoughts. In most cases the native language itself is able to offer definitions concerning issues of the local environment; however, due to the fact that no language exists alone, descriptions are often borrowed from other languages.

Recently, a significant number of definitions attempting to describe a loanword or a borrowing have been offered. Most linguists are in agreement that loanwords (or borrowings) tend to be the expressions transferred from one language into another (cf. Thomason and Kaufman, 1998; Heath [in:] Mesthrie, 2001; Myers-Scotton, 2006), but only a few linguists differentiate between loanwords and borrowings, claiming that loanwords are predominantly single words, whereas borrowings may range from stems to full phrases (Heath [in:] Mesthrie, 2001, p.432). In contrast to this claim, Myers-Scotton (2006) presents the opinion that there is practically no difference between the two descriptions, as both of them perform the same function, i.e. to define an activity of transfer of a word/phrase from a donor language to a recipient one.'

As to the types of loanwords, MyersScotton (ibid, pp. 212-215) remarks that two types exist - ones that reveal their native cultural origins and those which are of a core nature. Generally, cultural borrowings illustrate non-existent concepts in the lexicon of the recipient language, such as words/phrases referring to food, clothing or computers (or other technical) expressions, for example. Core borrowings, on the other hand, are usually words/phrases which have for one reason or another gained relative popularity in spite of their corresponding equivalents in the recipient language.

In this respect it may be of interest to analyse the functions performed by various lexemes and/or lexemic phrases that are borrowed from the donor language as core borrowings. As Calvet $(1987$, p.235) remarks, the term "borrowing" is only a technical one here, as in many cases such expressions are never given back, nor are they exchanged for some other phrases (produced by the recipient language). While being strongly critical of this situation, Phillipson (1993, p.7) adds that these forms of borrowings mostly go in one direction only and serve the current needs of the lexemes' users. Although any language may begin functioning as a donor one, it is usually the case that these functions are mostly performed by the language generally recognized as having wide global reach, i.e. most often used in the form of a

\footnotetext{
Actually, this expression (i.e. transference) was proposed by Clyne (1987), which has also become a phrase popular in the whole field of second-language acquisition.
} 
lingua franca. As currently the position of number one world language is occupied by English, it is various lexemes (and/or lexemic phrases) that are borrowed from this language and attempted to be anchored in other ones. According to Görlach $(1994$, p.23) during the last 100 years English has appeared to be the most expansive language in the world. Most of the phrases borrowed in this way, called Anglicisms, internationalisms, globalisms or Europeisms (depending on the position they have been spotted to be functioning in), can be observed to be active in many semantic areas of different recipient languages used for the purposes of communication in various parts of the world. As Täuschel (2008, p.15) observes, in many situations these borrowed phrases, on having been accepted and gaining an appropriately high level of functional use adjust themselves to both the phonological and spelling systems of the recipient languages. Although different tongues offer different semantic areas for these loanwords to be functionally used, it can be said (Görlach ibid, p.145) that there are some thematic categories which are particularly sensitive to the application of such phrases; mostly, they are observed in technology (and/or other areas of science), healthcare, economy, politics, fashion and/or politics, but very often they also appear in quite a number of everyday situations. This observation brings us into the area of everyday communication and the ways of its effective realization.

Quite a different approach to borrowings and loanwords emerges from the research carried out by Poplack, et al. (1988); the scholars suggest that loanwords are foreign expressions that commonly function in the recipient language whereas borrowings (or, as they are called here, "nonce borrowings") are the words/phrases that "(...) can only be integrated for the time of the conversation" (Poplack, et al. 1988, p.50). Additionally, Myers-Scotton (2006, p.254) remarks that most of the words are nouns. It is here where the discussion of whether there is a difference between a loanword and code-switching really begins. It is possible to assume that code-switching is an incidental situation of word/phrase borrowing, performed so as to more clearly illustrate the sense of an idea produced in a message and has little in common with the regular use of the word/phrase in the donor language (cf. Tatsioka, 2009, p.134-5).

A discovery that seems to appropriately shape and position the multi-layered research on the bonds of language, culture and communication is the commonly encountered claim (cf. Malamah-Thomas, 1988, p.11) that communication-dependent elements allow the producer of a message to decide upon the contents and quality of the message. This stance is based on the external forms of the communication-shaping process, such as traditionally used phrases and/or expressions that stem directly from local/general cultural norms. Additionally, it also backs Goffman's claim (1971) that people are never recognized for who they really are, as they are always expected to perform a traditionally ascribed role that meets the requirements of a situation people find themselves in (see: Goffman, 1971 , p.10ff). In this way, Goffman's interactional theory of communication sees people as acting out the roles ascribed to them by any of the local culture-requiring situations, with gestures, forms of body movement and language traditionally expected to appear in a given moment of interaction. The situation described here presents culture as a form of scaffolding upon which any form of behaviour can be found and adjusted to the currently required socially acceptable performance. It is believed that culture is the sector of human existence that fully directs everyday human functioning, language included. Consequently, language and culture are intrinsic elements of human society. This approach fully agrees with the one offered by Vygotsky (1986) and his claim on the importance of language in [child's] functioning [learning how to function].

Theories fully including language into human life and culture, as well as nominating it a symbol of human everyday functioning can be juxtaposed with another one, (cf. McKay, 2014), which sees language as a tool of communication that cannot be mixed combined culture. McKay claims that language is a mechanism applied to transfer a meaning enclosed in a message produced by its author. Culture is the reality that surrounds the message producer with little or no influence on the contents of the message especially when said message is transferred in a language not native to its author. A Pole (German, Spaniard etc.), using English as the basis for the construction of a message, is 
surrounded by a culture alien to the language found in the message, which should not have any influence on the structures and pragmatic rules applied to its construction. This approach logically brings forth the idea that there is no connection between a language (perceived as a message carrier) and a message (perceived as a product of the message producer's understanding of the external world) and that one can use whatever language to transmit the ideas born in one's mind. Culture is, thus, the sector of human life that helps people in the process of understanding the local environment as well as allowing the production of assessments related to the situation, the actual experience, but does not include language in any way.

Such a stance naturally results in a claim that a person using a language to produce a message must consider it as a handy mechanism s/he needs for the fulfilment of the purposes of communication, as well as there being, technically, no difference between a language and a tea-cup. Technically, both a language and a tea-cup are necessary to help people satisfy certain wishes, plans and/or endeavours, and that everything is a matter of skill (even if this approach is beheld from the point of view of tradition). Just like there are better (or worse) golfers or typists, there are also more or less proficient language users (this approach is not only limited to second-language users; it can also entail native-language users, if the issues of enculturation are taken into account).

The forms of presentation of ideas are also dependent on both internal and external conditions. If the author of a message has one particular receiver in mind, s/he selects the means of message transfer most suitable to both of them. If, however, there is no particular receiver, language is usually considered a general means of message transfer and more general (mostly written) means of information dissemination are used. Such general ways of information dissemination are selected mostly because of the existence of the Internet, where large opinion-shaping pieces are presented.

Naturally, when language has become disconnected from culture, all the characteristic structural/lexical figures (McKay calls them "norms") found in the given language have to be internalized by its users, but by no means are they to be understood as cultural illustrations of the language used (such an approach is described as imperialistic). Thus, McKay (2014, p. 49ff) clearly agrees with Phillipson (1986, pp.145-172) when he claims that too much foreign language delivered without appropriate heed of the learners' native language would result in the formation of (partial, at the least) shift within the learners' cognition towards the actual importance of any of the two (or more) languages in their future. The feeling that there are so-called prestige languages and that theirs, regrettably, does not fulfil this function may come to mind. At the same time such a situation could result in the subconscious introduction of a number of alien expressions into the internal tissue of the recipient language, and in this way, the borrowings more often than not would become natural segments of the native language.

\section{On the (im)practical application of Anglo-American English in the everyday existence of the world}

While discussing the reasons for the existence of a number of surprisingly similar expressions in a number of neighbouring languages Millward (1988, pp.8-10) enumerates, among others, an analogy which she calls the principle of least effort. The first issue, while being closely related to the second, explains the fact that similar rules/expressions can be observed functioning in two neighbouring languages (e.g. lack of articles in Slavic languages). The second issue relates to sociological background and claims that people are continually and consciously hunting for the expressions needed to define their own backyard (i.e. anything they do and/or describe in their local environment). In this way, one can observe that many of the expressions/phrases used to describe the environment in one language do appear in a second language. As Millward remarks (ibid., p. 5), it is not only single words or phrases but even ways of reasoning/understanding of the world that are often shared. It is quite common for metaphorical expressions to be formulated in a similar way, despite the fact that there is a small probability the two (or more) languages have ever crossed paths ${ }^{2}$. One of the possible explanations

\footnotetext{
2 For example, the expression as poor as a church mouse retains similar semantic (and sometimes even structural) form in quite a number of European languages, regardless of
} 
for this surprising situation (suggested by Millward) is the existence of a common ground for the majority of European languages, in spite of the fact that many of them have emerged from various language families.

The situation described above exemplifies the principle of least effort, assuming that people are quite content once an assessed expression sufficiently describes the notion they have come across and are currently in need of, which works well even in the most unexpected situations. There are many adequate examples to illustrate this observation, both in the past and in the ever-present language changing conditions. It is English itself which, from a language described by John Bullocar as corrupted (Millward, ibid, p.206), grew into a globally used as well as highly prestigious language. Due to the fact that a movement resulting in its strengthening with the help of classical languages (i.e. Latin and Greek) not only ended up a success but was also supported by many common users of the language (who believed that in order to let "the gods that be" hear and answer their prayers, a mutually understood, easy to follow language would be needed).

Consequently, English serves as the lingua franca of global communication. From the sociolinguistic point of view, English and especially its American variant has been recognized as a language one needs to comprehend in order to be a fully productive member of the ever-changing world community. This phenomenon is mostly due to the fact that Englishspeaking countries such as the United States not only perform leadership functions that are both politically and economically recognized but are also the most important drivers of the modern world. It is thus from this point of view that the American variant of English used by many for the purpose of communication (despite the fact that the American Constitution assures all the present and future citizens of the country to be equal, it does not dare to mention the language of communication to be used by the country's citizens) has commonly been accepted worldwide as the language necessary for communication.

Additionally, wishing to discern the influence of English (both British and

the part of Europe it comes from. Such linguistic behaviour can be traced in quite a large number of metaphors.
American variants) on the languages of the modern world (Slavic ones included) it is worth reiterating the research done by Kachru (1989, cf. Crystal, 1997), who analyses and explains the ways English has exerted its influence on the whole world. ${ }^{3}$ Following the research, Kachru divides the whole English-speaking world into three groups, labelling them Inner, Outer and Expanding circles, respectively. It is, however, the Inner Circle that is fully responsible for both the production and the internal changes of the English language (as this is the circle representing native users), whereas the Outer Circle (depicting the users of English as a second language of communication) is the circle where the rules/ways of application of the language are accepted, acclaimed and spread worldwide. What remains for the Expanding Circle is to foster the further growth and spread of English by making use of it among its contemporaries (without, however, a right to influence or change the language in any way). The only feature ascribed to the language users of the Expanding Circle is that by their numbers they validate English as a truly international language. Although an idea of what the concept of international English might mean in this respect has not been provided by Kachru, it can be inferred that the model assumes a pretty traditional function of the users of English within the Expanding Circle; they are to learn the language to be able to communicate with the inhabitants of the countries belonging to the two remaining circles. ${ }^{4}$

The people who, thus, make a more or less successful attempt to describe and define their thoughts, as well as to squeeze them down into emitted messages, depending on their current level of proficiency, are more or less

\footnotetext{
3 While discussing the ideas offered by Kachru, it is worth remembering that there are many inconsistencies in this model; for example, it is not clear what Kachru really wants to categorize here, in this way fusing several analytical levels (cf. Bruthiaux, 2003);

${ }^{4}$ It should be noted that while communicating with other inhabitants of their own countries they are obviously allowed to make use of any globalisms, internationalisms, and/or even Anglicisms transported into their languages they have learnt or know. It might be inferred that, following the stance offered by Phillipson (ibid.), or Poplack, et al. (ibid.) already discussed in this paper, the application of many Anglicisms can be quite a common phenomenon.
} 
successful. In trying to be understood by others, the speakers also create a picture of their own functioning in the second language used for message producing purposes. Unable to get rid of some of the most characteristic features of their native languages, not only do the users fall into numerous negative transfer-based traps but also strengthen the features to be observed in this (i.e lingua franca) international form of English-based communication. Smith (1976, [in:] McKay, 2014, p.12) specified the following three features of international English: a) no cultural features of the native language are expected to be internalized; $b$ ) it is not important who the owner of the language used by the users is; and c) what actually matters is the communication of the ideas, regardless of the quality of the communication itself. In this way, one can say that international English is supposed to be culturally anonymous and its principal function is to carry out successful communication. It is not relevant whether one has fully mastered all the structural/lexical rules existing in the language (save the ones acknowledged as the most basic, or else one could have problems with the communication itself), nor if these or any other mandatory rules have been internalized and correctly applied but whether the intended meaning has successfully been delivered to the message recipients. As a result, international English has often been described as stereotypical, rugged, jerky and difficult to follow (cf. Sztencel, 2009). Nevertheless, it is also in this way that many successful attempts to carry messages in said language have been effected.

\section{The ways (over)excessive use of English seems to influence a native language}

Naturally, following the observations offered by Millward (see above) such excessive use of a language recognized as a prestigious one must influence the functioning of the native language, which can be observed with respect to English (but not only) message producers. Such an assertion actually means that any expression (or phrase) that does not correspond to the expression (or phrase) functioning in the native language and which has been assessed in the semantic description as less relevant will most likely be liable to intrusive change. This approach incorporates the assumptions of the use of English as an international language formulated by Brutt-Griffler (2002, [in:] McKay 2014, pp.12-13) who claims that a) the use of English reveals both an international and local character; b) no connection with the messagelanguage culture can be observed; c) the only culture that has a right to appear in a message produced by non-native use of English is a local one; d) it is mostly such local culture-emerging ideas that have a right to be revealed (and spotted) by any non-native user of this form of English. In most cases the influence of international English on other languages can be assessed on the principle of mutual semantic closeness of the two languages. Naturally, the process of description of the local environment is hindered by the appearance of a number of loanwords, which may either appear as expressions semantically as important as the ones functioning in the native language or simply replace the native expressions.

While making an attempt to uncover the unique issues specified above, it is necessary to state the following: a) the appearance of native English expressions performing the functions of international ones ${ }^{5}$ can influence and help construct the semantic definitions appearing in the users' native language, provided that the number of native (i.e. non-English) language users accepting the application of a given (foreign, i.e. English) phrase/expression is large enough to recognize it as a phrase borrowed for good; b) a phrase/expression accepted as fully fitting the descriptive processes in the users' native language is incorporated into the native culture by means of its recognition as a correctly described cultural artefact; c) the scope of its national circulation (and, in this way, its

\footnotetext{
5 The most obvious way of borrowing a word from English by some other language is with the help of the so-called International English (IE) lexicon; in other words, the most likely to be borrowed are words which have been successfully recognized as popular enough in the appropriate semantic circles of the International English lexicon. At the same time, it is worth mentioning that such an IE lexicon, following the estimations of VoA Special English, 2001, appears to be more or less stable and may only be enlarged in exceptional situations (such as the invention - and subsequent linguistic definition/description of a new gadget that may greatly influence and/or modify the life of its users).
} 
general popularity) depends on the rate of acceptance of a phrase/expression by an unspecified number of native users of the language. ${ }^{6}$

There is one more issue to be analysed in discussing the phenomenal influence and co-functioning of various languages in the area of world communication. That is, the way a stronger language (and any language generally recognized as prestigious must be stronger) influences and evokes changes in a weaker one. It is not only the case of the Young People's Dyirbal, a language used by an Australian tribe, that was doomed due to overexcessive influence of English but also a number of other languages that followed the same fate. ${ }^{7}$ Any language that has been indisputably recognized by its users as stronger (i.e. better representing their individual interests) will prevail in the process of their personal choice as to what language to nominate in order to express thoughts/messages in daily attempts to communicate. Unless the officially recognized native language is nominated, its further existence is questionable.

An attempt to explain and describe such interdependence can be found in a very interesting paper by $M$. Sztencel (2009). The processes described there are very interesting and worth broader analysis. Apart from the fact that, according to the author, the Polish alphabet has become larger (due to the acceptance of such letters as $x, q$ and $v$, for example), Sztencel presents a detailed analysis of the changes that have occurred (or are occurring) in the Polish language, basing her assumptions/claims on the research carried out by herself and other academics. One of interesting issues Sztencel discusses is a scale formed by two linguists; Thomason and Kaufmann (1998, [in:] Sztencel, 2009, p.15) prepared a four-level scale, whose aim is to analyse the closeness of any two (or more) languages moving towards each other, both in terms of syntactic and semantic closeness. The researchers take into account a language recognized as international, on the one hand, and any language deemed to be less popular (that is, a language that plays a less important role in communication), on the other. This

\footnotetext{
${ }^{6}$ This is, among others, the process experienced by such English-born terms as: hamburger, hot-dog, joystick, design, layout, outfit and many others.

7 See a very interesting book by A. Dalby (2002) on the topic in question.
}

scale ranges from the initial phase of sporadic contacts (mainly lexical borrowings), through borrowings of function words (as well as some phrases illustrating language structural capacities), up to the appearance of the third phase (borrowing a number of terms of a basic nature used to describe a number of phenomena of extra-linguistic reality). This is followed by the final, fourth, phase where the level of borrowings from an international language into the native language is already very high. Using, for example, the forms of research proposed by Sztencel (op.cit.) to present a analysis of contemporary the Polish language, i.e. a language that previously did not have any extensive contacts with the English language, it must be admitted that 1) the level of interdependence of both languages is significant and that 2) the contemporary Polish language has not only adapted a series of original English terms (some to such a significant extent that today they are regarded as constituent elements of the Polish language) but also some structural forms. ${ }^{8}$ In many aspects, the research we describe below fully backs this hypothesis.

\section{Analysing the ways Polish and English co-operate (?)}

Before such an analysis is empirically effected, let us summarize the situation so far. On the one hand, assuming that clear bonds between a language and the culture it emerges from exist, all languages are expected to not only describe the culture but also to become one of its most important constituents. Following Kramsch (1998, p.13) language describes the cultural reality it is surrounded by. As any language is expected to describe only one cultural reality, any other [new] cultural reality would need a new language, i.e. a language that was purposefully formed to suit the ways of understanding this new reality by its native users. Such a situation might suggest that any non-native user of a language wanting to define a cultural reality in a non-native language would be expected to jump into the cultural shoes

\footnotetext{
8 This situation may result, for example, in the appearance of the phenomenon of language equivalence (or its various forms) that will be much more clearly perceived by many Polish users of English, considering this language as the language of communication, which in many cases should play a vital role in the whole process of creating their interlanguage, if the target language is English.
} 
of the native users in order to discover the ways cultural reality is perceived and described. On the other hand, there are many proponents who are not sure such a situation is [technically] possible. McKay (see above) is of the opinion that technically it is neither possible nor probable for an inexperienced non-native user of a target language (such as a FL learner, a tourist, or a business manager) to come mentally close to the "enchanted chamber" of the semantics of the language used by native speakers in order to share the feelings and/or experiences stored there. This is why non-native users only need to practise some norm-based expressions to be able to transpose their thoughts into a non-native language. This opinion is also shared by Kachru (1989) when he suggests the existence of three mutually dependent circles of human responsibility for the development and functioning of English. In placing nonnative users of English within the Expanding Circle, Kachru indicates that not only are they unable to develop English semantically but also should never be appointed to do so.

A model similar to the one proposed by Kachru may be applied to describe the functioning of most languages, as in any language it is possible to specify both the Inner Circle, where all the inherent rules and regulations referring to its functioning can be established and the Expanding Circle, meant to be used by all non-native users of the language who wish to apply it for communicational purposes. Additionally, in the case where said language functions as the second official language in a given country the Outer Circle should also appear. However, it is the Inner Circle which is of primary interest when all the vital aspects of linguistic functioning are to be discussed, e.g. the nature of mutual interplay between the native language and all other languages it co-exists with. The influence of a global language (such as English) on recipient languages also constitutes an important aspect of mutual interest. What should be addressed first are the issues connected with the numerous linguistic descriptions of cultural reality by native users of English.

It would be easy enough to address these issues on condition that no contact between a global language and a recipient one exists. However, such a situation is never likely to occur and Millward (ibid, pp.1-12) offers a number of convincing and explanatory reasons why it is never possible for any two neighbouring languages to keep on functioning separately. One reason, which she does not seem to stress strongly enough, is a highly motivated desire to be able to express oneself in a most precise way while describing/formulating one's opinion on a given aspect of reality. Many people (and especially those who are relatively fluent in more than one language) are often tempted to apply some foreign (i.e. borrowed) expressions which in their opinion contain a description better defining the underlying issues they have planned to express. Some of these borrowed descriptors tend to fill up the cultural voids existing in the recipient language, but others seem to be just trendy slogans. Usually, at first, the application of such borrowed expressions does not exceed the boundaries of codeswitching, thus being an example of individual sporadic usage. However, after a number of such expressions have gained considerable popularity, they are usually transposed into the recipient language lexicon. This is the moment when the language either approves of them (mostly when they are of a cultural nature) or makes an attempt to offer them an additional semantic sub-sectional area they can be appointed to (cf. Heath [in:] Mesthrie, 2001, p.432). Situations allowing loanwords to fully replace native words are scarce. What appears to be more common are situations in which the original expressions either fully (or partially) change their original semantic designations or join the inventory of abandoned ones (see the Compendium of Lost Words, 2014, with respect to English).

Another issue that needs to be clarified and explained is what causes some of the loaned words/phrases to become so widely infused and deeply ingrained in the borrowing language. What is the nature of such borrowings? What comes first, an urgent need to fill a cultural void, or an impromptu discovery of the cognitive expression of an idea one wishes to define (often under the mistaken impression that the loanword comes from a prestige language)?

These were some of the main issues of the current research. In planning the questionnaires we wanted to trace the many paths that borrowed words/phrases take in order to reach the level of acceptance in the mental lexicon of the recipient language (in this case Polish). 
Does the fact that the borrowings appear in print in renowned national magazines indicate their acceptance by the lexicon of the language used by journalists? What must happen to enable the recognition of such borrowings as elements of the Polish lexicon? What is the level of cognitive coverage (as well as social understanding) of each of the borrowings found in the national magazines? Is it possible, based on the research results, to establish which borrowings still remain at the level of code-switching and which ones have already been incorporated into the main body of the national lexicon?

Naturally, the current research concentrates upon the issues related to our previous research (Polok, 2012). Its principal aim is to establish the extent and means by which a dominant international (donor) language such as English, influences a subordinate less fashionable (recipient) one such as Polish. In the previous (2011) research we attempted to discover possible forms of transfer of English loanwords into the Polish language as well as the further implementation thereof (if it really took place). We managed to establish that there are at least five different ways a borrowing language makes use of an English loanword: 1) it makes use of its illustrative segment only, in this way replacing it for the one already existing in the native language with the semantic segments remaining unchanged (e.g. the not very successful attempt to replace the, largely popular in Polish, globalism bar with the English $\left.\operatorname{pub}^{9}\right)$; 2) a brand new cognitive concept is introduced together with its illustrative segment (e.g. the introduction of fast-food into Polish); 3) two words - a (fashionable) loanword and a (mostly descriptive, but linguistically wellgrounded) globalism - begin to function inter-changeably (e.g. aerobic vs. gimnastyka dla kobiet /cvičenie pre ženy ${ }^{10}$ ); 4) the illustrative element of the loanword is given its native (Polish) label-like equivalent (e.g. steam engine vs. maszyna

\footnotetext{
9 Actually, here is a situation when an earlier borrowed Anglicism (i.e. bar) is pushed away by a new (and currently more fashionable) one; as it seems, the reasons are clear enough: semantically bar is perceived as a place where some dishes can be eaten quickly (and also some, not necessarily alcoholic, beverages drunk), whereas the lexeme pub is semantically mostly connected with beer-drinking activities. ${ }_{10}$ In each case we have provided the Slovak translation of the Polish expression.
}

parowa/ parný stroj ); 5) the borrowed concept is given its native verbal illustration, where the accepted native expression is partly linked with the nature of the loanword (e.g. bicycle vs. rower/bicykell'). Another conclusion of the aforementioned research was a discovery that a form of defence applied by the weaker subordinate language initiates a search for a semantic niche within the borrowing language, so that finally the loanword usually indicates a situation somewhat semantically different from the one so far observed in the native language of the loanword (cf. already discussed in the recent research introduction of the English event into Polish, where a new semantic area for the lexeme has been offered ${ }^{12}$ ).

The purpose of the current research was not only to discover if and how the accepted loanwords influence comprehension of the environment, but also whether one can find any forms of implantation of the Anglo-American perception of the world in describing the local language environment. Based on the observation of the ongoing situation and the fact that various expressions illustrating such styles of life have been approved and accepted by Poles, two questionnaires were necessary. In order to ascertain the integrity of these issues the first questionnaire focused upon the semantic comprehension of expressions found in a pilot study. The expressions mentioned above achieved a relatively high (i.e. more than 40\%) popularity among our respondents. The second questionnaire concentrated on certain styles of communicational behaviour evoked by the introduction and common application of the expressions.

\subsection{Description of the research}

Preparation for the research consisted of two steps; the first one required a selection of up to 30 (finally we decided to close the list at 29) Anglicisms (such as welfare state, face lifting, or spin-doctor, for example) that, hypothetically, have been achieving relative popularity in Polish (assessed from the point of view of the frequency of use of each of the selected

\footnotetext{
1 The Polish expression clearly indicates the place the first bicycles were produced, i.e. the Rover Factory in Coventry.

${ }^{12}$ An event being an unusual, not often observed and spectacular activity; in this way, the lexeme approaches Polish wydarzenie/udalost.
} 
functional phrases). This assessment was based on a pilot study carried out in the form of analysis of two Polish popular periodicals, i.e. "Newsweek" and "Polityka", and especially the issues published between November 2015 and February 2016, from which all the expressions were extracted. Due to the popularity and large circulation of the two Polish periodicals, we assumed that the language used in the periodicals was not only understood by their readers but also recognized as commonly used forms of description relevant to the subject at hand. The general idea was that it is the media which performs an important function in popularizing the process of certain expressions borrowed from many foreign (currently, mostly English) languages. Journalists, as professionals who are required to describe and define the environment in an exact and succinct way are known to apply many foreign expressions whose semantic traces may be figured out contextually. Consequently, as far as our hypothesis went, many of the forms used are later to be accepted by the native readers of the periodicals and, subsequently, applied independently.

The total number of magazine articles searched through reached a figure of 546 . Due to the fact that the articles discussed various unrelated topics, most of them had no foreign (English) expressions. As a result, the number of articles in which the borrowings were found came down to 61 , which for the purpose of this research equals $100 \%$. The following phrases were chosen from the aforementioned Polish periodicals: body-building, bubble gum, call center (call centre), call girl, car leasing, credit card, disc-jockey, exchange rate, face lifting, fan page, fast food, goalkeeper, head hunter, hi-fi, hot dog, love affair, mass media, office manager, print screen, red alarm, show business (show biz), soap opera, spin doctor, standby, think tank, top secret, trade mark, welfare state, wi-fi. Now, we were able to establish a number of popular "favourites" functioning in such phrases as car leasing (10 articles - 16.39\%), spin doctor (9 articles - 14.75\%), body-building (8 articles - 13.12\%), hot-dog (13 articles - 21.31\%), love affair ( 7 articles - 11.46\%), show business (show biz) (8 articles - 13.12\%), or think tank (5 articles - 8.20\%). Additionally, the fact that the specified borrowings were used in at least three articles, without any explanations, qualified said borrowings to be inserted in the questionnaire. Finally, when such a list was completed in the form of a questionnaire, we decided to look for possible respondents.

The respondents (171 young men and women, students of various colleges, universities and secondary schools located in southern Poland) were asked to 1) indicate which Anglicisms they normally use when taking part in casual conversations and 2) give interpretations of the borrowed phrases (in case they had not come across a loanword before, or were not sure of the meaning, they were asked to place a minus next to a phrase, or simply leave it untouched). The reason we focused on young users of Polish was that, generally speaking, young people are more open to many new descriptions of oncoming reality. Thus, due to the relatively high popularity of English in such groups the probability of having made use of many expressions in everyday (i.e. Polish) verbal communication was more likely. In the questionnaires the respondents were not only asked to indicate the forms they use, but also to provide translations of the phrases they currently do not use but could, if necessary, apply to describe the environment. In this way we also wanted to find out how well the phrases are understood or how much the general understanding differs from the actual meaning of the phrases.

\subsection{Results of the research}

The results obtained not only showed a group of "favourite" phrases, i.e. the ones most commonly used by the respondents, but also the phrases that were less popular, or not popular at all. The most popular phrases appeared to be the ones that are widely used in society and are currently recognized as the expressions that have almost lost all the features of foreignness: fast food (94.74\%), wi-fi (92.98\%), hot dog (91.23\%), print screen (75.44\%), hi-fi (73.10\%), fan page (71.93\%), and credit card (69.01\%). On the other hand, there were expressions that were ticked very sporadically, despite their relative popularity in the media: love affair (9.94\%), spin doctor (9.36\%), think tank (4.09\%), and especially welfare state, which was not been ticked by any of the respondents $(0.00 \%)$. The borrowings that indicated relative popularity: top secret (53.80\%), show business (52.05\%), mass media (51.46\%), car leasing (43.86\%), bubble gum (42.10\%), call center (41.52\%), 
or face lifting (39.18\%), are also among those whose meanings were not always correctly explained. The expression face lifting, for example, was approached either from the mechanical or medical side, however, the medical interpretation of the borrowing prevailed over the mechanical one (29.24\% to only $9.94 \%$ ).

A significant number of expressions were given incomplete or even false interpretations, whereas many more were given outline translations, which indicated a rough location of the borrowing within a certain semantic field only; for example, the borrowing body building, apart from its correct translations, was defined by the following outline interpretations: gym, steroids, body sculpting, fitness, or even trainer. Similarly, the expression head hunter produced quite a number of rough (as well as many completely incorrect) semantic indications, such as: killer, paparazzi, horror, head covering (!), work, boss, TV film, police forces, or mercenaries. Generally, almost all (save the most popular) borrowings we listed produced some outline interpretations, which only roughly indicated the core meaning of the phrase. This tendency became more prevalent when the borrowing was less popular or the exact meaning was more intricate. An example of such behaviour can be spotted in the borrowing think tank, where the following (mostly false) interpretations were offered: thin tank (!), car refuelling, refills at the $K F C$, or even thoughts about life. Only a few respondents (out of those that ticked a possible use of the phrase) were able to offer the correct meaning of the borrowing i.e. stating that this phrase indicates a body of experts providing advice and ideas on specific political or economic problems. Similarly, which seemed to be quite strange because we thought the phrase to be well and safely grounded, a high number of outline (or incorrect) interpretations were found with the borrowing show business, where the respondents offered the following meanings: business, making money, catwalk shows or celebrities.

Another relevant result can be observed when one attempts to contrast the expressions that received high ratings in the pilot study with their actual recognition by the respondents. Although such borrowed phrases as hot-dog, car leasing or even show business were rated very high, at the top of the list, the same cannot be said about the remaining top scorers from the pilot study; body-building (39.18\%) placed in the middle of the list, and the three remaining ones i.e. spin doctor (9.36\%), love affair (9.94\%) and think tank (4.09\%) at the bottom of the ratings. Such contradiction may generate considerable interest, as one might expect that the very fact that these loanwords were so popular among journalists would automatically mean they would be widely recognized by the respondents (readers). A possible explanation for this fact may be that either the respondents do not fully understand the semantic areas covered by each of the indicated and lowly rated loanwords, and/or they do not read carefully. It is possible that the reading process is often focused on the leading topic of an article, with some of the loanwords that are not fully comprehended by the readers simply read and passed over without being understood. Such a situation naturally means that the loanword has not been widely disseminated and can be classified as either an example of code-switching, or an illustration of a nonce-borrowing specified by Poplack et al. (1988).

The situation above cannot be fully applied to the loanword love affair, which was also poorly rated by the respondents. The low position of the loanword may result from the fact that a preferable calque-like equivalent exists in the Polish language. The fact that the phrase was so popular among those found in the pilot study could also be explained as another illustration of code-switching of the magazine authors. Similar references can be made to a number of other loanwords which were also moderately rated by the respondents: red alarm (33.92\%), soap opera (33.92\%), head hunter (32.74\%) or even bubble gum (42.10\%). Each of the aforementioned expressions seems to function on the principle of close native equivalents, which appear to be a barrier in the dissemination of the loanwords in the recipient language.

We were also interested in the average number of borrowings that were indicated by the respondents. Not only could such a figure let us know how well a given respondent is familiar with the borrowings listed, but it could also inform us as to the frequency of usage of the English expressions that (in a way) keep infiltrating into the Polish system of descriptions of the local environment. The statistical calculations establish the figure to be near 11 borrowings (11.27), which 
suggests that the average force of the borrowing trend among Polish users of the language may have reached its lower limits, ${ }^{13}$ thus as it seems, quite innocuous to the language.

Actually, the questionnaires revealed unexpected information concerning the respondents' attitude towards a probable introduction of the borrowings into day-today communication. It seems that the respondents are not willing to make use of the expressions used by the media if they are able to find a native expression that represents the idea, or if they are not sure the loanword has been fully adapted in Polish. Offering the interpretations of the listed phrases, many respondents presented close translations of the borrowings, especially in respect to the phrases that had already been offered translations by the media. Such a situation was observed in the case of credit card (98.18\% of close translations of the phrase), soap opera (87.75\%), head hunter (67.15\%), trade mark (67.03\%), and bubble gum (62.23\%); this suggests that many of the respondents are not inclined to start using the borrowed phrases if a native equivalent exists. Only if a borrowing has been fully accepted by the mother tongue are the respondents willing to make use of it. This situation is mostly represented by fast food (94.74\%), wi-fi (92.98\%) or hot dog (91.23\%), which scored the three top results on the list. Additionally, two more high scoring borrowings hi-fi (73.10\%) and fan page (71.93\%) seem to be on track to be fully adapted and used by the speakers of the mother tongue. It is worth noticing that all of the borrowings refer to recent cultural phenomena and indicate activities which otherwise require long descriptive deliberations in the mother tongue. On the other hand, such a high percentage was not observed in the case of some similarly behaving borrowings such as top secret (53.80\%), show business (52.05\%), mass media (51.46\%) or disc-jockey (only 34.50\%).

\subsection{Discussion}

The research described above provided quite a few novel observations. The very first thing to be asserted is that there are a number of borrowed expressions which are not treated as loanwords by Polish

\footnotetext{
13 Thomason and Kaufman (1998) do not offer exact figures when discussing the level of weaker (recipient) - stronger (donor) language interdependence.
}

users because they, for the most part, follow the rules of grammar common for the Polish language such as case declension, for example. These are not only such phrases as fast food, hot dog, or wi-fi (which scored highest among the respondents), but also a couple of others, such as print screen (75.44\%), hi-fi (73.10\%), fan page (71.93\%), and even credit card (69.01\%). Such a result may suggest that quite soon these expressions will no longer be considered loanwords in the language (just as the two, or even three, highest scoring phrases) and will start being used as expressions that have gained full semantic rights of the language that borrowed them. In fact, such symptoms can already be observed in respect to the phrase fan page, which is already being inflected in all grammatical cases that can be found in the Polish language. A similar situation may be observed in the case of print screen, also inflected (although not so openly) by many people dealing with IT sciences.

These are just two examples of cultural loanwords that have been widely introduced into the recipient language while functioning on the principle of least effort specified by Millward (1988). Following the analysis of word change as presented by Millward, it is the functioning of the principle of least effort which appears to be the most tempting and/or successful possibility for an introduction or exchange of a donor language expression into the recipient language. As the recipient language has no accurate expression to define an item obviously functioning in the scope of general language reality, an attempt is made to borrow such a word from another (usually more powerful) language and adapt it so that the loanword starts performing similar functions in the new language.

Another relevant observation (also partly backing our hypothesis concerning the process of word/phrase nesting in the Polish language) is the fact that many of the analysed expressions underwent a process of word splitting, despite the fact they had entered Polish as illustrative examples of prefabricated phrases. Such a situation can be observed in respect to the phrase face lifting, for example. The semantic idea hidden in the phrase in question turns the speakers' attention to the process of restoring an old and tired face to look younger, the semantic notion of the gerund lifting indicates a process of partial reconstruction of a not fully 
accepted body into a form that may have better chances for acceptance. Describing such an idea with the help of the word lifting seems to be fully approved by many people who have started using it in varied situations (when describing political reshuffles of the Cabinet, for example)..$^{14}$ Additionally, the word lifting follows the rules of case declension, which clearly indicates its incorporation into Polish. ${ }^{15} \mathrm{~A}$ very similar situation, both in respect to phrase splitting and the independent use of gerunds, can be observed in another researched phrase, namely car leasing, where the word leasing can also be observed to function independently of the word car. ${ }^{16}$ Whereas, the borrowed expression body building, which clearly illustrates the same structural pattern in English, has not followed the process observed in the two phrases specified above and still functions as a unified indication of a wish to sculpt one's body with the help of heavy gymnastics apparatus.

Introducing a borrowed word/phrase into the native declension system seems to be the most obvious symptom of its incorporation into the native mental lexicon. However, there are still quite a few borrowed phrases that clearly do not follow this procedure, despite the fact that they are as popular as the borrowings which are in the Polish declension system. In some cases the situation seems to be clear, as Polish has offered a close, mostly translation-based equivalent (as in the case of bubble gum, credit card or love story), but still in many remaining situations the borrowed expressions have retained their original features (cf. top secret, call girl, red alarm, call center, office manager, trade mark, or think tank). One possible explanation may be that all these borrowed phrases have not reached the level of - as it may be called general frequency of use yet and thus still remain restricted to certain semantic conditions.

Another reason for the research was to uncover if and how the researched and largely accepted loanwords have influenced the forms of cognitive

\footnotetext{
${ }_{14}$ Cf. Newsweek, 40/2016, p.46

15 This phenomenon refers to a totally assimilated borrowing, also called morphemic adaptation (cf. Täuschel, 2008, p. 12).

${ }_{16}$ Cf. the Polish branch of Credit Agricole invites its probable customers with the ad slogan: Leasing - napęd dla twojego biznesu! (Leasing - drives your business forward!)
}

comprehension of the socio-cultural environment in the loanword countries (in this instance, Poland). Assuming that any language construes, even subconsciously, certain forms of description of the perceived environment, one needs to comprehend the semantic picture in making an attempt to grasp the meaning of the words/phrases received in the language. We state that the reason some expressions are accepted more easily by the recipient languages, whereas some others need more time to do so, is the fact that these expressions/phrases contain semantic features that more clearly describe the socio-cultural and sociopolitical situation in a given country. In this way, we put forth the hypothesis that certain borrowed phrases which have gained such popularity as to be commonly incorporated into another language clearly illustrate a foreign (Anglo-American) perception of the world smoothly corresponding with the imaginary construal of other societies. Not being able to clearly verbalize these assumptions, foreign users of these phrases apply them to indicate some features they would like to follow and actively incorporate into the functioning of their own societies. Such an approach may mean that 1) language users feel that their mother tongue requires modifications or changes both in the syntactic and semantic areas; 2 ) that the semantic areas offered by the loanwords may be recognized as offering interesting enough forms of description of the local environment, so far unknown (or undiscovered) in the mother tongue; and 3 ) that (at least) some of the borrowings may be recognized as mother tongue fertilizing material, actively influencing the creative factor of the borrowing tongue.

An example indicating the reasonableness of this assumption is the (already partially discussed) behaviour of the loanword lifting in the Polish language; although originally lifting meant raising to a higher level of position (OALDoCE, 1982, p. 489), its meaning was clearly modified in the Polish language, after the highly accepted borrowing face lifting was deemed attractive enough for the semantic purposes of its Polish users; following OALDoCE (p.304), the original definition of face lifting is a medical one and reads: operation of tightening the skin to smooth out wrinkles and make the face look younger. Apart from that, it is worth observing that the whole borrowing has 
recently been given another, technical meaning in referring to the reconstruction of an old car. The research carried out indicated that only $10 \%$ of the researched respondents opted for the technical application of the borrowing. At the same time, as mentioned earlier, the gerundial segment of the expression has started to be used in its new semantic denotation of reconstructing (or even restoring) something old and/or unfashionable so as to let it regain a new look. In this way, the Polish language has started to tolerate such partly metaphorical expressions as government lifting, or landscape lifting. ${ }^{17}$ Additionally, it is worth recognizing that these and similar words/phrases either tend to appear in the situations describing their authors' reformist attitude or, as in the lexeme event mentioned some time earlier (as well as in the footnote below), in situations fully accepting the implementation of such unusual and seldom-heard-of activity.

Quite a varied picture can be obtained in carrying out the analysis concerning the understanding (and further supposed application) of many of the borrowings placed on the research list (cf. p. 14). Generally, it may be asserted that many of the respondents were either unable to offer their own interpretations of the researched phrases (in this instance, they left the appropriate questionnaire box empty), or made an attempt to offer close (and/or following a stereotypically equivalent) native translations. Such a situation can be seen in respect to a number of the researched borrowings, many of which possessed strong native equivalents (e.g. credit card, exchange rate, bubble gum, soap opera, love affair, or head hunter). Nonetheless, there were quite a few borrowings whose translations seemed puzzling to us and probably resulted from incomplete or inaccurate understanding of the originals. In this way, the borrowing think tank sometimes produced bizarre interpretations such as "a kind of small tank" $(2.01 \%$ of the respondents), or "thoughts about life" (1.76\% of the respondents). Similar bizarre interpretations could be found in a few of the other borrowings, such as show

\footnotetext{
17 A very similar situation can be found in respect to the borrowed lexeme event in Polish, which - contrary to the original meaning of the word (cf. OALDoCE, p.293) - tends to indicate something spectacular, unusual and hardly imagined in the language.
}

business (up to $0.36 \%$ of respondents suggested as an equivalent meaning catwalk show, and $0.27 \%$ suggested a very general description of celebrities), head hunter, (sporadic translations being killer, headgear, paparazzi, TV series, or mercenaries) or body building (some of the respondents offered largely generalized ideas, such as the gym, steroids or fitness coaching).

Finally, there was one borrowing which, partly against our initial expectations, clearly revealed the negative attitude of the majority of the respondents to the semantic idea hidden behind it. Despite the fact that the respondents indicated that they understood the semantic loan hidden behind the phrase call girl, a significant number wrote that they were not willing to make use of the expression, because it indicates a situation they are morally against. There were even sporadic responses (two such cases) where the respondents openly wrote that they were not going to fill in this questionnaire box because they disapproved of such immoral situations. As for the possible interpretations of the borrowing in question, many were standard (and elegant) translations of the equivalent phrase functioning in Polish (a girl who can be summoned by phone to accompany lonely people - mostly men). Nonetheless, many respondents called a spade a spade and used straight-forward or even vulgar expressions (a prostitute, a harlot or a whore). Additionally, there were also a few bizarre explanations of the borrowing, such as: a call to a girlfriend (1.03\% of the respondents), or a girl working at the post office who helps one call some other person $(0.75 \%$ of the respondents). Generally, it can be said that the level of acceptance of this borrowing (although it cannot be denied that it does appear in many Polish publications) is doubtful. On the one hand, it cannot be said that it is not known and understood by the respondents $(23.97 \%$ of them stated that they were aware of its meaning); on the other hand, however, $76.02 \%$ of the respondents declared they were not inclined to make use of it in their daily communication, clearly preferring the native (i.e. Polish) descriptions.

\section{Conclusions}

The research showed a polarized picture of the whole situation, indicating that some forms of semantic correspondence between the two languages do exist and 
even develop in some situations; however, it also defined the limits of such cofunctioning, thus validating the conclusions drawn during our previous research. The most significant result of the research was the discovery of novel measures used by a subordinate weaker recipient language to concede to the widely accepted loanwords/phrases of a global donor language. As uncovered in our previous research, the most popular form of concession, mostly when it is no longer possible to remain impervious to the repeated intrusions of globally accepted meanings, is an attempt to find a new, thus far unknown niche within the semantic body of the weaker language and insert the new finding there. Thus, as indicated earlier, the loanword is usually allowed to describe a situation a little bit semantically different from the one so far observed in the native language of the loanword. Such a conclusion can be drawn when observing the situation and the forms of treatment in respect to such borrowings as face lifting, car leasing, or mass media. In each case, either the whole phrases, or one of their parts, have been used in novel situations.

In many situations, usually when a functional native lexeme or phrase has been formed, the borrowing is not very popular, often being perceived as an expression of secondary vicarious importance. Such a conclusion can be drawn by a number of borrowings with literal native translations (e.g. bubble gum, credit card or exchange rate). ${ }^{18}$ However, in case no new native translation has been found, a borrowing is accepted and introduced into the native semantic system either with small syntactic changes or even without any modifications at all. In this way, the borrowing fan page, indicating a brand-new social situation, followed the way of such borrowings as palmtop, laptop, computer, hamburger, hot dog and many others. The aforementioned borrowings were introduced into the native declension system and treated as one of many native expressions. Nevertheless, other borrowings which, mostly due to native phonetic rules, cannot be easily

\footnotetext{
${ }_{18}$ These are examples of Anglicisms which are not expected to behave in a functional way. Yule (1998, p. 65) calls them calques. Crystal (2003, p.27) defines them as "(...) lexical items which are part-by-part translated into another language."
}

introduced into the indigenous syntactic system usually remain unchanged (e.g. hifi or wi-fi); as a result, they remain treated as foreign introductions, despite their generally high level of semantic popularity.

Finally, borrowings which have clear indications of possessing foreign phonetic heritage (even when they appear necessary in the ongoing productive processes that ought to result in the creation of semantically close picture-like ideas) are treated with suspiciousness and mistrust. Consequently, in many cases said borrowings seem to be left as second choice possibilities, with the native (even descriptive) forms being preferred. A good example of such a situation is the history of such borrowings as love affair, soap opera, spin doctor, think tank or even trade mark; in each case a native (often longer) expression was normally chosen by the respondents. Generally, it seems that Polish language users not only prefer traditional native expressions but also (when necessary) make use of the existing word/phrase borrowing possibilities, under the condition that the borrowings are better equipped to define and describe the ever-changing environment. 


\title{
References
}

BOGACKI, K. and KAROLAK, S., 1991. Założenia gramatyki o podstawach semantycznych. In: Język a kultura; wiedza o kulturze, vol. 8, pp. 157-188.

BRUTHIAUX, P., 2003. Squaring the circles: Issues in modeling English worldwide. International Journal of Applied Linguistics, no. 13, pp. 159-179.

BRITT-GRIFFLER, J., 2002. World English; a study of its development. London: Multilingual Matters.

CALVET, L.J., 1987. La guerre des languages et les politiques linguistiques. Paris: Payot.

CLYNE, M., 1987. Constraints on code-switching: how universal are they? Linguistics, no. 25, pp. 739-64.

Compendium of Lost Words - The Phrontistery. Available at: http://phrontistery.info/clw.html.[Accessed 30 October 2016].

CRYSTAL, D., 2003. The Cambridge encyclopedia of the English language. Cambridge: Cambridge University Press.

CRYSTAL, D., 1997. English as a global language. Cambridge: Cambridge University Press.

DALBY, A., 2002. Language in danger. London: Penguin.

GOFFMAN, E., 1971. The presentation of self in everyday life. London: Harmondsworth.

GÖRLACH, M., 1994. More Englishes. New studies in varieties of English 1988 - 1994. Amsterdam: Benjamins.

HEATH, J., 2001. Borrowing. In: R. Mesthrie, ed. Concise encyclopedia of sociolinguistics. Oxford: Elsevier Science Ltd, pp. 432-442.

HORNBY, A.S., 1982. Oxford advanced learner's dictionary of current English (OALDoCE). Oxford: Oxford University Press.

KRAMSCH, C., 1998. Language and culture. Oxford: Oxford University Press.

MALAMAH-THOMAS, A., 1988. Classroom interaction. Oxford: Oxford University Press.

McKAY, S., 2014. English as an international language. Oxford:Oxford University Press.

MILLWARD, C. M., 1988. A biography of the English language. New York: Harcourt Brace Jovanovich.

MYERS-SCOTTON, C., 2006. Multiple-voices: An introduction to bilingualism. Oxford: Blackwell.

PAIVIO, A., 1986. Mental representations: A dual coding approach. Oxford: Oxford University Press.

PHILLIPSON, R., 1993. Linguistic imperialism. Oxford: Oxford University Press.

POLOK, K., 2012. Artykuł o pożyczkach. Polonistyka 2011, Medisont, pp. 469-505.

POPLACK, S., SANKOFF, D. and MILLER, C., 1988. The social correlates and linguistics processes of lexical borrowing and assimilation. Linguistics, no. 26, pp. 47-104.

SCHMIDT, A., 1985. Young People's Dyirbal. Cambridge: Cambridge University Press.

SMITH, L., 1976. English as an international language. RELC Journal, no. 7/2, pp. 3-43.

SZTENCEL, M., 2009. Boundaries crossed: The influence of English on Modern Polish. Episteme, vol. 2, no. 1, pp.3-17.

TATSIOKA, Z., 2009. Code-switching and English loanwords in the Greek media. Available at: http://www.ncl.ac.uk/linguistics/assets/documents/9.Zoi_Tatsioka-FT.pdf. [Accessed 30 October 2016].

TÄUSCHEL, A., 2008. Anglicisms and their influence on other Languages. Frankfurt (Main): University of Frankfurt (Main) Press.

VYGOTSKY, L., 1986. Thought and language. Chicago: MIT Press.

UR, P., 2007. A course in language teaching: Practice and theory. Cambridge: Cambridge University Press.

YULE, G., 1998. The study of language. Cambridge: Cambridge University Press.

\author{
Author's address and contact details \\ Doc. Krzysztof Polok, PhD. \\ Faculty of Humanities \\ University of žilina \\ Univerzitná 8215/1 \\ 01026 Žilina \\ Slovakia \\ E-mail: sworntran@interia.pl
}

